\title{
PENGARUH PELATIHAN, PENGEMBANGAN DAN KEPUASAN KARYAWAN TERHADAP KINERJA KARYAWAN DI PT XYZ
}

\author{
Violeta Laurensia \\ Program Studi Magister Manajemen Universitas Tarumanagara \\ violetalaurensia@gmail.com
}

Masuk : 30-11-2019, revisi : 20-12-2019 diterima untuk diterbitkan : 21-12-2019

\begin{abstract}
Human resource is one of the most important aspects of an organization. There are several indicators that can influence human resources which include but not limited to training, development, performance, and satisfaction. The goal from this research is to analyze the effect of training on employees' performance, to analyze the effect of development on employees' performance, to analyze the effect of employees' satisfaction on their performance, and to analyze the effect of training and development on employees' performance in PT XYZ. The sample size in this study is 70 people. The method used in this study is quantitative and the instrument used is questionnaire which is then analyzed using SPSS 22. The results are: (1) Training have a significant influence on employees' performance ( $p$-value $<0.05,0.004)$, (2) Development do not have a significant influence on employees' performance ( $\mathrm{p}$ value $>0.05$, 0.473), (3) Employees' satisfaction have a significant influence on employees' performance (p-value < 0.05, 0.00), (4) Training and development have a significant influence on employees' performance (sig. value $<0.05$ in the Anova test, 0.00).
\end{abstract}

Keywords : Employee training, employee development, employee performance, employee satisfaction

Abstrak : Sumber daya manusia merupakan salah satu aspek penting yang terdapat dalam perusahaan. Terdapat beberapa indikator yang dapat berpengaruh terhadap sumber daya manusia yaitu pelatihan, pengembangan, kinerja, dan kepuasan. Tujuan dari penelitian ini adalah untuk menganalisis pengaruh pelatihan terhadap kinerja karyawan, untuk menganalisis pengaruh pengembangan terhadap kinerja pada karyawan, untuk menganalisis pengaruh kepuasan karyawan terhadap kinerja karyawan, dan untuk menganalisis pengaruh pelatihan dan pengembangan terhadap kinerja pada karyawan di PT XYZ. Sampel yang diambil berjumlah 70 orang. Metode dalam penelitian ini bersifat kuantitatif dan instrument yang digunakan dalam penelitian ini adalah kuesioner yang dianalisis dengan SPSS 22. Hasil dari penelitian menghasilkan: (1) Pelatihan memiliki pengaruh yang signifikan terhadap kinerja karyawan (p-value < dari 0.05, 0.004), (2) Pengembangan memiliki pengaruh yang tidak signifikan terhadap kinerja karyawan (p-value > 0.05, 0.473), (3) Kepuasan Karyawan memiliki pengaruh yang signifikan terhadap kinerja karyawan (p-value $<0.05,0.00$ ), (4) Pelatihan dan pengembangan memiliki pengaruh yang signifikan terhadap kinerja karyawan (nilai sig. $<0.05$ pada tes Anova, 0.00).

Kata kunci : Pelatihan karyawan, pengembangan karyawan, kinerja karyawan, kepuasan karyawan 


\section{Pendahuluan}

Menurut Dessler (2010) menajemen sumber daya manusia adalah proses untuk memperoleh, melatih, dan mengompensasi karyawan, dan untuk mengurus relasi tenaga kerja, kesehatan dan keselamatan karyawan, serta hal-hal yang berhuungan dengan keadilan.

Kinerja merupakan sebuah tolak ukur untuk menilai pencapaian tujuan organisasi. Salah satu cara untuk meningkatkan kinerja karyawan dalam organisasi adalah memberikan program pelatihan dan pengembangan pada karyawan.

Pelatihan dimaksudkan untuk memperbaiki penguasaan berbagai keterampilan dan teknik pelaksanaan pekerjaan tertentu, terperinci, dan rutin (Handoko, 2001).

Simamora (2004) mendefinisikan pengembangan karyawan sebagai aktivitas pengembangan karir karyawan terhadap organisasi, penyediaan landasan bagi karyawan agar dapat berprestasi secara efektif dan menghasilkan prestasi baru dalam lingkungan perusahaan.

Davis dan Newstrom (1985) mendeskripsikan kepuasan kerja adalah seperangkat perasaan karyawan tentang menyenangkan atau tidaknya pekerjaan mereka.

\section{Masalah}

1. Apakah terdapat pengaruh signifikan pelatihan karyawan terhadap kinerja karyawan?

2. Apakah terdapat pengaruh signifikan pengembangan karyawan terhadap kinerja karyawan?

3. Apakah terdapat pengaruh signifikan kepuasan karyawan terhadap kinerja karyawan?

4. Apakah terdapat pengaruh signifikan pelatihan dan pengembangan karyawan secara simultan terhadap kinerja karyawan?

\section{Pembahasan \\ Pelatihan}

Armstong (2006), mengemukakan bahwa pelatihan adalah penggunaan kegiatan pengajaran yang sistematis dan terencana untuk mempromosikan pembelajaran. Menurut Noe (2003), pelatihan mengacu pada upaya terencana oleh perusahaan untuk memfasilitasi pembelajaran karyawan tentang kompetensi terkait pekerjaan. Menurut pendapat diatas maka dapat disimpulkan bahwa pelatihan adalah pengalaman belajar dengan kegiatan pengajaran yang sistematis dan terencana untuk mencari perubahan yang relatif permanen pada individu yang akan meningkatkan kemampuan untuk bekerja.

\section{Pengembangan Karyawan}

Menurut Nawawi (2005), pengembangan adalah suatu proses pengembangan minat dan bakat untuk karyawan dalam kesempatan menaiki jabatan yang lebih tinggi dalam suatu perusahaan.

Sedangkan menurut Armstrong (2006) pengembangan adalah suatu proses yang berlangsung untuk memungkinkan orang untuk maju dari keadaan pemahaman dan kemampuan saat ini ke keadaan masa depan dimana keterampilan, pengetahuan, dan kompetensi tingkat tinggi diperlukan. Menurut pendapat diatas maka dapat disimpulkan bahwa pengembangan adalah proses yang berorientasi pada masa depan yang memungkinkan orang untuk maju dari keadaan pemahaman dan kemampuan saat ini ke keadaan masa depan dimana keterampilan, pengetahuan, dan kompetensi yang tinggi diperlukan.

\section{Kepuasan Karyawan}

Menurut McShane (2018), kepuasan karyawan adalah evaluasi seseorang terhadap pekerjaan dan konteks kerjanya, hal tersebut adalah penilaian karakteristik pekerjaan yang dirasakan, lingkungan kerja, dan pengalaman emosional ditempat kerja. Menurut Robbins (2003), kepuasan karyawan didefinisikan sebagai suatu sikap umum seorang individu terhadap pekerjaannya. Berdasarkan pendapat diatas dapat disimpulkan bahwa kepuasan karyawan 
adalah suatu sikap umum seorang individu yang mencerminkan perasaannya terhadap pekerjaan, konteks kerjanya, dan segala sesuatu yang dihadapi dalam lingkungan kerja.

\section{Kinerja Karyawan}

Menurut Mangkunegara (2009), kinerja adalah hasil kerja secara kualitas dan kuantitas yang dicapai oleh seorang pegawai dalam melaksanakan tugasnya sesuai dengan tanggung jawab yang diberikan kepadanya. Sedangkan menurut Mathis and Jackson (2002), kinerja adalah apa yang dilakukan atau apa yang tidak dilakukan karyawan untuk menacapai hasil dari suatu pekerjaan, dan menurut Ivancevich (2007), kinerja merupakan pondasi kinerja dalam organisasi.

\section{Gambaran Umum PT XYZ}

PT XYZ berdiri pada tahun 1989 memiliki kantor pusat yang terletak di Jakarta Pusat. PT XYZ bergerak dibidang perkebunan / agronomi, tumbuhan utamanya adalah kelapa sawit. Selama PT XYZ beroperasi PT XYZ telah memiliki kantor cabang di Kota Samarinda, juga beberapa perkebunan kelapa sawit di Kalimantan. Selain kebun inti yang dikelola oleh PT XYZ sendiri, PT XYZ juga menjalin kerjasama dengan mitra petani kelapa sawit setempat untuk membangun dan mengelola kebun yang disebut dengan kebun plasma. PT XYZ memiliki jumlah karyawan 45 di kantor pusat dan 25 di kantor cabang Samarinda. Selain itu, PT XYZ memiliki sejumlah 1000 dibagian operasional perkebunan. Secara keseluruhan ada sekitar 1070 orang yang menjadi bagian dari PT XYZ.

\section{Uji Validitas}

Uji validitas dilakukan dengan tujuan untuk menjamin bahwa kuesioner yang digunakan untuk mengumpulkan data merupakan kuesioner yang valid. Sebuah kuesioner dikatakan valid apabila mampu mengukur apa yang diinginkan dan dapat mengungkap data dari variabel yang diteliti secara tepat. (Sugiyono, 2014). Uji yang akan digunakan dalam penelitian ini ialah $U j i$ Korelasi Pearson Product Moment. Dalam uji ini, setiap item akan diuji relasinya dengan skor total variabel yang dimaksud. Apabila harga taraf signifikansi yang dihasilkan kurang dari 0,05 maka butir yang diuji dinyatakan valid.

\section{Uji Realibilitas}

Uji Reliabilitas menunjuk pada suatu pengertian bahwa sesuatu instrumen cukup dapat dipercaya untuk digunakan sebagai alat pengumpul data karena instrumen tersebut sudah baik. (Arikunto, 1993). Penelitian ini menggunakan metode uji reliabilitas melalui Alpha Cronbach. Pengujian dilakukan dengan menggunakan harga Alpha Croanbach. Keputusan pengujiannya, apabila hargaAlpha Cronbach lebih besar dari 0,60 maka instrumen dinyatakan reliabel.

\section{Analisis Regresi}

Persamaan regresi digunakan mengetahui bentuk hubungan antara variabel bebas dengan variabel terikat. Bedasarkan hasil yang diperoleh maka didapatkan persamaan regresi sebagai berikut: $\mathrm{Y}=0,159+0,309 \mathrm{X} 1+0,070 \mathrm{X} 2+0,450 \mathrm{X} 3$

\section{Koefisien Determinasi $\left(\mathbf{R}^{2}\right)$}

Hasil koefisien determinasi pada model regresi sebesar 0,496, maka dapat diartikan bahwa 49,6 persen kinerja dapat dijelaskan oleh variabel pelatihan karyawan, pengembangan karyawan, dan kepuasan karyawan. Sedangkan sisanya sebesar 50,4 persen dipengaruhi oleh variabel lain yang tidak dimasukkan dalam model penelitian. 


\section{Hasil Pengujian Hipotesis}

\begin{tabular}{|c|l|c|}
\hline Hipotesis & \multicolumn{1}{|c|}{ Hipotesis } & Keterangan \\
\hline H1 & $\begin{array}{l}\text { Terdapat pengaruh signifikan dari pelatihan karyawan terhadap } \\
\text { kinerja karyawan }\end{array}$ & Terbukti \\
\hline H2 & $\begin{array}{l}\text { Terdapat pengaruh signifikan dari pengembangan karyawan } \\
\text { terhadap kinerja karyawan }\end{array}$ & $\begin{array}{c}\text { Tidak } \\
\text { Terbukti }\end{array}$ \\
\hline H3 & $\begin{array}{l}\text { Terdapat pengaruh signifikan dari kepuasan karyawan terhadap } \\
\text { kinerja karyawan }\end{array}$ & Terbukti \\
\hline H4 & $\begin{array}{l}\text { Terdapat pengaruh signifikan dari pelatihan karyawan dan } \\
\text { pengembangan karyawan terhadap kinerja karyawan }\end{array}$ & Terbukti \\
\hline
\end{tabular}

\section{Kesimpulan}

1. Pelatihan karyawan secara parsial memliki pengaruh yang signifikan terhadap kinerja karyawan PT XYZ.

2. Pengembangan Karyawan juga secara parsial tidak memiliki pengaruh signifikan terhadap kinerja karyawan PT XYZ.

3. Kepuasan Karyawan memiliki pengaruh yang signifikan terhadap kinerja karyawan PT XYZ

4. Pelatihan karyawan dan Pengembangan Karyawan secara simultan memiliki pengaruh signifikan terhadap kinerja karyawan PT XYZ.

\section{Saran}

Saran yang dapat diberikan oleh peneliti adalah PT XYZ perlu melakukan evaluasi terhadap pelatihan dan pengembangan karyawan yang dilakukan oleh perusahaan kepada karyawan, PT XYZ dapat memberikan fasilitas yang lebih mendukung bagi para karyawan untuk berlatih dan berkembang agar karyawan dapat bekerja dengan maksimal dan dapat berpengaruh terhadap kinerja karyawan itu sendiri terutama lebih banyak melakukan program pengembangan agar para karyawan merasa lebih berkembang dalam bekerja. PT XYZ juga hendaknya meningkatkan kepuasan kerja karyawan, contohnya memberikan gaji, tunjangan, bonus, dan kesempatan promosi sesuai dengan asas keadilan, baik adil secara individual, secara internal maupun secara eksternal agar karyawan puas dan akan loyal terhadap perusahaan. Dalam rangka meningkatkan kepuasan kerja karyawan, diharapkan karyawan lebih serius lagi dalam mengikuti pelatihan dan pengembangan yang diberikan oleh perusahaan, agar nantinya pengalaman dan ilmu yang didapat dapat diterapkan di perusahaan dan memperbaiki kinerja karyawan itu sendiri. Karyawan PT XYZ diharapkan dapat melakukan kinerjanya sebaik mungkin sehingga dapat memberikan kontribusi terhadap perkembangan perusahaan. Karyawan hendaknya meningkatkan pengetahuan, keterampilan, dan penguasaan informasi mengenai pekerjaan yang harus diselesaikan. Peneliti selanjutnya bisa menggali informasi lebih dalam mengenai PT XYZ, dan dapat menambahkan variabel penelitian, misalnya kompensasi, disiplin kerja, dan K3. Bagi peneliti selanjutnya juga diharapkan dapat meneliti lebih lanjut mengenai budaya organisasi yang ada di PT XYZ.

\section{Daftar Pustaka}

Arikunto, Suharsimi. (1993). Prosedur Penelitian Suatu Pendekatan Praktek. Jakarta: Rineka Cipta.

Armstrong, Michael. (2006). A Handbook of Human Resource Management Practice 10th Edition. London: Kogan Page.

Davis, Keith dan John W. Newstrom. (1985). Perilaku Dalam Organisasi. Jakarta: Erlangga.

Dessler, G. (2010). Dalam Manajemen Sumber Daya Manusia (D. Angelia, Penerj., 14th ed., hal. 12). Jakarta: Salemba Empat. 
Handoko, T. Hani. (2001). Manajemen Personalia dan Sumberdaya Manusia. 2nd ed. Yogyakarta: BPFE.

Ivancevich, dkk. (2007). Perilaku dan Manajemen Organisasi. Jakarta: Erlangga.

Mangkunegara P. Anwar. (2009). Manajemen Sumber Daya Manusia Perusahaan. Bandung: PT Remaja Rosdakarya Offset.

Mathis, Robert dan Jackson, John. (2002). Manajemen Sumber Daya Manusa. Jakarta: Selemba Empat.

McShane dan Glinow. (2018). Organizational Behavior. 8th ed. New York: Irwin McGrawHill.

Nawawi, Hadari. (2001). Manajemen Sumber Daya Manusia untuk Bisnis yang Kompetitif. Yogyakarta: Gajah Mada University Press.

Noe, Raymond. A. (2003). Human Resource Management, Internasional Edition. New York: The McGraw-hill Companies, Inc.

Robbins, DeCenzo. (1996). Human Resource Management 5th Edition. Canada: John Wiley \& Sons, Inc.

Simamora, Henry. (2004). Filsafat Ilmu dan Metode Riset. Medan: Usu Press.

Sugiyono. (2007). Statitika untuk Penelitian. Bandung: CV Alfabeta. 